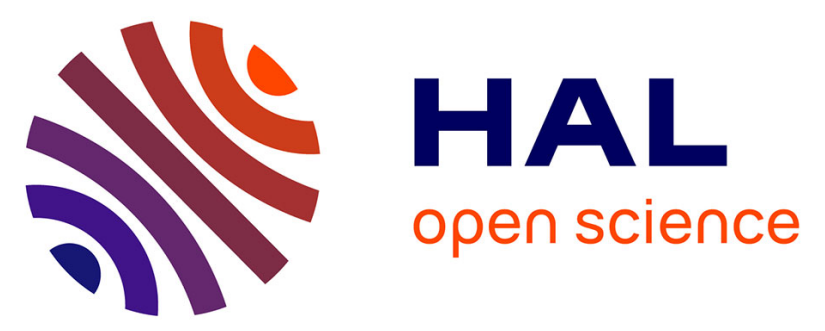

\title{
Mechanical effects of oxidation induced shrinkage on organic matrix composites
}

Ahmed Yousfi, Sylvain Fréour, Mohamed Rahmani, Hocine Osmani, Frédéric Jacquemin, Djelloul Gueribiz

\section{- To cite this version:}

Ahmed Yousfi, Sylvain Fréour, Mohamed Rahmani, Hocine Osmani, Frédéric Jacquemin, et al.. Mechanical effects of oxidation induced shrinkage on organic matrix composites. ACMA 2010, 2010, Marrakech, Morocco. hal-01008401

\section{HAL Id: hal-01008401 https://hal.science/hal-01008401}

Submitted on 21 Nov 2018

HAL is a multi-disciplinary open access archive for the deposit and dissemination of scientific research documents, whether they are published or not. The documents may come from teaching and research institutions in France or abroad, or from public or private research centers.
L'archive ouverte pluridisciplinaire HAL, est destinée au dépôt et à la diffusion de documents scientifiques de niveau recherche, publiés ou non, émanant des établissements d'enseignement et de recherche français ou étrangers, des laboratoires publics ou privés. 


\title{
Mechanical effects of oxidation induced shrinkage on organic matrix composites
}

\author{
Yousfi Ahmed $^{1 *}$, Fréour Sylvain ${ }^{2}$, Rahmani Mohamed ${ }^{1}$, Osmani Hocine ${ }^{3}$, Jacquemin \\ Frédéric $^{2}$, Gueribiz Djelloul ${ }^{4}$. \\ ${ }^{1}$ Mechanical Laboratory, University Amar Telidji of Laghouat, Algeria. \\ ${ }^{2}$ GeM - Institut de Recherche en Génie Civil et Mécanique, UMR CNRS 6183, \\ Université de Nantes - Ecole Centrale de Nantes, France. \\ ${ }^{3}$ Nonmetallic Materials Laboratory, University Ferhat Abbas of Setif, Algeria. \\ ${ }^{4}$ Laboratory of engineering process, University Amar Telidji of Laghouat, Algeria. \\ * Corresponding author: a.yousfi@mail.lagh-univ.dz
}

\begin{abstract}
The present work is focused on investigating the effects, due to the shrinkage, on the mechanical states occurring in composites structures made of organic matrix having been subjected to a thermal-oxidation process. The oxidation actually induces some matrix shrinkage which is reported to generate high local stresses. In the present work, effective mechanical properties of oxidized composite plies are determined according to EshelbyKröner self-consistent homogenization procedure, depending on the progress of the oxidation process. The results are compared to the corresponding properties estimated by the finite element method. The macroscopic stresses undergone by each ply of the structure submitted to typical loads are deduced from the classical lamination theory and
\end{abstract}


by the finite element method, whereas the local stresses in both constituents are calculated for each ply of structure, through an analytical stress concentration relation.

\section{Keywords: thermo-oxidation / shrinkage / polymer matrix composites / scale transition models / local stress.}

\section{Introduction:}

Composites materials based on high glass transition temperature matrices are likely to be used as structural parts for next generation aircraft and, thus, will have to face oxidative atmosphere at moderate or high temperatures (typically 100$300^{\circ} \mathrm{C}$ ) during several thousands of hours [1]. The lifetime scheduled for the structural elements of supersonic aircraft approximately corresponds to 20,000 cycles in a range of temperatures varying between $-55^{\circ} \mathrm{C}$ and $120^{\circ} \mathrm{C}$, with a total length of the plateau at $120^{\circ} \mathrm{C}$ of $80,000 \mathrm{~h}$ (10 years) [2]. Such high temperatures over long periods cause a thermal ageing of the organic matrix constituting the composite parts leading to thermal oxidation of the material external plies. The problem occured when such organic matrix composites have been considered for applications under severe environmental conditions (temperatures of about $250^{\circ} \mathrm{C}$, air pressure higher than 1 atmosphere) [3, 4]. The laminated composites exposed to high temperatures are subject to degradation caused mainly by thermal oxidation of their organic matrix. It induces the growth of oxidized layer of reduced thickness in the subsurface of the composite parts. This superficial phenomenon leads to weight loss and alters the mechanical behavior of the material [5-7], inducing a fragility of its subsurface, the properties of which are different to those of the bulk, generally remaining unaffected by oxidation. The purpose of this work is the multiscale analysis of the consequences of the thermal-oxidation of epoxy matrices on the 
intrinsic mechanical properties of the external composite ply, on the one hand, and on the internal mechanical states of composite structure according to the considered mechanical loading, on the other hand. This work includes five sections following this introduction. The second section is dedicated to the influence of thermal oxidation on the mechanical properties of composite ply. The third section presents Eshelby-Kröner self-consistent model: its constitutive laws are given for the estimation of effective thermal elastic properties of composite ply (stiffness tensor and coefficients of thermal expansion). The fourth section is devoted to the coupling of the classical lamination theory and analytical scale-transition relations for local stress determination in both constituents of composite plies subjected to a thermo-elastic loading. The fifth section describes the conclusions of the present study.

\section{Effective properties of a thermo-oxidized composite ply}

\subsection{Oxidation model and results}

Various models enabling to achieve the numerical computation of oxidation process in pure epoxies or epoxy matrix composites have been proposed in the literature $[8,9]$. Simulations of isothermal aging at $150^{\circ} \mathrm{C}$ of an epoxy resin demonstrated that the oxidized layer thickness was not growing beyond $200 \mu \mathrm{m}$ whereas the oxidation products concentration were continuously increasing in the affected layer [7]. Ultra-micro indentation tests on epoxy resin, after $100 \mathrm{~h}, 600 \mathrm{~h}$ and $1000 \mathrm{~h}$ of isothermal aging at $150^{\circ} \mathrm{C}$ show that a relation between elastic indentation modulus and oxidation products concentration occurs (Eq. 1) [7]:

$\mathbf{Y}^{\mathbf{m}}=5479-1460 \mathbf{E x p}(-0.79 \mathbf{Q})$

where $\mathrm{Y}^{\mathrm{m}}$ is the elastic modulus of the epoxy matrix, expressed in GPa, while Q is the oxidation products concentration (mol/L). The corresponding profile for $\mathrm{Y}^{\mathrm{m}}$ is displayed 
on figure 1. The matrix is considered as an isotropic material, which Poisson's ratio $v^{\mathrm{m}}=0.35$ is assumed, due to the lack of available information on its evolution, as independent of the state of thermal oxidation process.

The oxidized matrix is stiffer than the unaffected matrix in a ratio varying between 1 and 1.38. The matrix properties of a thermally oxidized ply can be very different from those of the corresponding unaffected ply, so that three main consequences due to the thermal oxidation of composite structure can be expected: a variation of $i$ - the effective macroscopic properties of composite plies, ii- the profiles of macroscopic stress in the structure and iii- the localization of the macroscopic mechanical states (stress and strain) in both constituents of each ply (fiber and matrix). The three above listed expected consequences of thermo-oxidation are multi-scale phenomena, either explicitly, in the case of items i- and iii-, (i- being an homogenization problem, whereas iii- is related to localization problem), or implicitly, in the case of item ii-, which implies the knowledge of the macroscopic effective properties of the composite ply (resulting from the estimates achieved in i-). In order to be able to treat each of these aspects, a scale-transition model is required. This model is described below in Section 3.

\section{Multi-scale Analysis}

\subsection{Introduction}

Mean-field scale transition models involve a multi-scale representation of the studied materials. In the case of composite materials, the following two-scale model is often sufficient:

- The macroscopic scale corresponds to that of the composite ply. It is denoted by the superscript ${ }^{\mathrm{I}}$, whereas, 
- the so-called "pseudo-macroscopic" [10] properties and mechanical states of the constituents (either the resin or its reinforcements,) are respectively indicated by the superscripts ${ }^{\mathrm{m}}$ and ${ }^{\mathrm{f}}$.

The composite structure is actually constituted by an assembly of the above described composite plies, each of them possibly having the principal axis of their reinforcements differently oriented from one to another. This approach enables to treat the case of multidirectional laminates, as shown, for example, in [11]. In the present work, the local properties of the i-superscripted constituents are considered to be known (i.e. the pseudomacroscopic stiffnesses, $\mathbf{L}^{\mathbf{i}}$ and coefficients of thermal expansion $\mathbf{M}^{\mathbf{i}}$ ), whereas the corresponding effective macroscopic properties of the composite structure (respectively, $\mathbf{L}^{\mathbf{I}}$ and $\mathbf{M}^{\mathbf{I}}$ ) are a priori unknown and results from computations.

Among the numerous, available in the literature scale transition models, able to handle such a problem, most involve rough-and-ready theoretical frameworks, such as: Voigt [12], Reuss [13], Neerfeld-Hill [14-15] Tsai-Hahn [16] and Mori-Tanaka [17, 18] approximates In spite of the lack of the physical realism of the mathematical framework involved in the aforementioned models, some of them do nevertheless provide a numerically satisfying estimation of the effective properties of a composite ply, by comparison with the experimental values or others, more rigorous models. Both TsaiHahn and Mori-Tanaka models fulfill this interesting condition [19, 20]. Nevertheless, in the field of scale transition modelling, the best candidate remains Kröner-Eshelby selfconsistent model $[21,22]$, because this model takes into account a rigorous treatment of the thermo-hygro-elastic interactions between the homogeneous macroscopic medium and its heterogeneous constituents, as well as this model enables handling the microstructure (i.e. the particular morphology of the constituents, especially that of the reinforcements). 


\subsection{Determination of the effective macroscopic thermo-elastic properties of} composite plies

Within Eshelby-Kröner self-consistent model, the homogenization law relating the macroscopic elastic stiffness of a composite ply to the properties of the constituents is:

$\mathbf{L}^{\mathbf{I}}=\left\langle\mathbf{L}^{\mathbf{i}}:\left[\mathbf{E}^{\mathbf{I}}:\left(\mathbf{L}^{\mathbf{i}}-\mathbf{L}^{\mathbf{I}}\right)+\mathbf{I}\right]^{-1}\right\rangle_{\mathrm{i}=\mathrm{f}, \mathrm{m}}$

In equation (2), I stands for the fourth-order identity tensor, whereas Hill tensor, or Morris tensor $\mathbf{E}^{\mathbf{I}}$ (depending on which work from [28-29] is considered) expresses the dependence of the localization tensor on the morphology assumed for the matrix and its reinforcements [28]. Its components are functions of the macroscopic stiffness $\mathbf{L}^{\mathbf{I}}$ (some examples are given in $[23,24])$.

The homogenization relation satisfied by the macroscopic coefficients of thermal expansion of a composite ply writes as follows:

$$
\mathbf{M}^{\mathbf{I}}=\mathbf{L}^{\mathbf{I}^{-1}}:\left\langle\left[\mathbf{E}^{\mathbf{I}}:\left(\mathbf{L}^{\mathbf{i}}-\mathbf{L}^{\mathbf{I}}\right)+\mathbf{I}\right]^{-1}: \mathbf{L}^{\mathbf{i}}: \mathbf{M}^{\mathbf{i}}\right\rangle_{\mathbf{i}=\mathrm{f}, \mathrm{m}}
$$

Only a few study studies were dedicated to the oxidation effects on the mechanical behavior of organic matrix composites. It was nevertheless shown in [25] that the properties of carbon fibers are stable below $300^{\circ} \mathrm{C}$. As a consequence, the variation of mechanical properties of thermo-oxidized laminates only depends on the evolution of the matrix properties. Table 1 displays the local properties of carbon fiber considered in order to achieve the homogenization calculations.

Evolutions of the effective longitudinal and transverse macroscopic elastic moduli, as a function of the oxidation products concentration are shown on Figures 2 and 3, for a composite containing a carbon fiber volume fraction equal to $60 \%$. The effective mechanical properties of the oxidized composite ply were determined, during the 
oxidation process, through Eshelby-Kröner self-consistent homogenization procedure (Eq. 2) (curve "KESC"). The results were compared to the corresponding properties estimated according to the finite element method (FEM "curve").

Figure 4 shows the evolutions obtained for the effective macroscopic coefficients of thermal expansion of a composite ply, according to equation (3), during the thermal oxidation process experienced by the epoxy. According to figures 2 and 4 , the longitudinal effective properties (i.e. in the direction parallel to axis of the reinforcing fibers), are, in first approximation, independent from the state of thermal oxidation process of the polymer matrix constituting the considered composite ply. Actually, a relative deviation weaker than $1 \%$ is observed at the end of the oxidation process for the Young's modulus, while the longitudinal macroscopic coefficient of thermal expansion remains almost constant (and tends towards zero).

This result is explained by the fact that in the fiber direction, a unidirectional ply presents thermo-mechanical properties which are controlled by the properties of a single constituent: the fiber. Experimental results on composite plies in similar circumstances, i.e. in cases when the carbon fibers exhibit constant properties, while those of the matrix significantly vary, corroborates the results of our simulations: longitudinal effective macroscopic properties of composite plies do not vary as a function of the properties polymer matrix (at least in the case that the composite ply contains a high volume fraction of fibers) [27]. On the contrary, the effective macroscopic properties of a composite ply, in the direction transverse to the reinforcements axis, do significantly depend on the state of thermal oxidation process experienced by the polymer matrix constituting the ply. In fact, the relative variation of transverse Young modulus of oxidized ply compared to the reference value (unaffected ply) can reach $12 \%$ at the term of oxidation process (and spreads so that the variation for transversal coefficient of 
thermal expansion is $3.5 \%$ ). This effect strongly depends on the volume fraction of reinforcements in the composite ply and may reach $38 \%$ in the pure matrix at the end of the oxidation process.

\section{Study of the multi-scale mechanical states experienced by the composite structure}

\subsection{Matrix shrinkage effect on the mechanical states of the thermo-oxidized composite}

The matrix was modeled as undergoing two time-dependent processes, and the fibers were assumed to be stable (i.e. impervious to any oxidation effects on their properties). The first process is a matrix mechanism that is partly an extension of the cure process, in which the matrix changes by chemical and physical aging. This mechanism, which depends on temperature and time, is associated with small amounts of matrix shrinkage and mass loss (less than 1 percent) and with density and material property changes. In thermoset materials, this mechanism is dominated by changes in chemical cross-linking, so the mechanism will be

referred to here as the cross-linking mechanism. The second process is a degradation mechanism due to oxidation and/or another mechanism that breaks down the polymer structure of the matrix. Temperature and oxygen availability govern this mechanism. In thick parts of the matrix, this mechanism appears to be diffusion limited and, thus, occurs mostly on the surface, causing material property changes (mostly degradations) and mass loss. Mass can be lost by erosion of the surface (making the part smaller), formation of voids, reduction in density of the matrix, or shrinkage of the matrix. In practice, density changes are 
not observed, whereas some void formation and major shrinkage are observed [30]. This second mechanism will be referred to as the mass-loss mechanism. When matrix shrinkage occurs (i.e. in oxidative environment), the high strain gradients present in matrix areas, close to fibres which have a very high stiffness, lead to high local stresses that can be favorable to fibre/matrix debonding or to crack initiation [31]. The total strain in matrix $\boldsymbol{\varepsilon}_{\mathbf{T}}^{\mathbf{m}}$ is:

$$
\varepsilon_{\mathbf{T}}^{\mathbf{m}}=\varepsilon_{\mathbf{E}}^{\mathbf{m}}+\varepsilon_{\mathbf{S}}^{\mathbf{m}}
$$

Where $\varepsilon_{\mathrm{E}}^{\mathrm{m}}$ is the elastic strain of matrix, whereas $\varepsilon_{\mathrm{S}}^{\mathrm{m}}$ which denotes the strain due to the shrinkage of matrix, depends on its oxidation state.

$$
\boldsymbol{\varepsilon}_{\mathbf{S}}^{\mathbf{m}}=\left[\begin{array}{ccc}
\delta_{11}^{\mathrm{m}} & 0 & 0 \\
0 & \delta_{11}^{\mathrm{m}} & 0 \\
0 & 0 & \delta_{11}^{\mathrm{m}}
\end{array}\right] \mathrm{Q}
$$

where $\delta_{11}^{\mathrm{m}}=\frac{\varepsilon_{\mathrm{S}}\left(\mathrm{Q}_{\max }\right)}{\mathrm{Q}_{\max }}$, and $\varepsilon_{\mathrm{S}}\left(\mathrm{Q}_{\max }\right)=2,5 \%$ is the maximal strain due to the matrix shrinkage [32].

The matrix shrinkage associated to degradation causes deformations at the ply level. The fibers are assumed to be dimensionally stable, and hence restrain the shrinking of the matrix. This behavior is analogous to the thermal expansion of a ply consisting of a fiber and a matrix with different thermal expansion coefficients. It results in a macroscopic strain that is intermediate between the strain that would be experienced by the unrestrained matrix material, from the one hand and the bare fiber, one the other hand. 


\subsection{Determination of mechanical states within the constituents of a composite ply subjected to thermo-elastic loading:}

Analytical relations satisfying the fundamental assumptions of Eshelby-Kröner selfconsistent model, enabling to proceed to the localization of the macroscopic strains within the matrix were established in [11]. Due to the length of these equations, they will not be provided in the present work, so that the interested reader should refer to equations $(18-19)$ of [11]. The variation of the internal macroscopic stresses $\sigma_{11}^{\mathrm{I}}$ and $\sigma_{22}^{\mathrm{I}}$ has been calculated during the one edge thermal oxidation process of a composite laminate submitted to either a longitudinal or a transverse external load. The results obtained for the macroscopic mechanical states were localized within the constituents using the above described scale transition relations. The curves obtained for both the macroscopic and local stresses experienced by the external ply of a composite structure, submitted to a transverse mechanical load, have been displayed on figures 5-6. The effect of thermooxidation and the superposition of thermo-oxidation and shrinkage effect are displayed on figure 5-6 respectively. On the same figures, the stress states predicted for the thermooxidized laminate were compared to the corresponding stresses calculated for the unaffected material. The mechanical states predicted from the effective macroscopic properties provided by Eshelby-Kröner Self-Consistent model were also compared to the mechanical states calculated from the effective macroscopic properties deduced from finite elements analysis.

Figures 5 and 6 underline the consequences of a shrinkage induced by thermal oxidation on the multi-scale mechanical states. When the composite plate is submitted to a transverse mechanical loading, the internal stresses experienced by the oxidized ply and its very constituents differ from those that would have been undergone by an unaffected 
ply: the macroscopic stress increases during the thermal oxidation, as a consequence of the increased effective stiffness of the thermo-oxidized ply. At the scale of the constituents,

i) the stress concentration in the reinforcing fiber does not vary at all as a function of the oxidation products concentration, since the properties of the carbon fibers are unchanged during the thermal-oxidation process.

ii) the epoxy matrix experiences an increasing stress state during the thermal oxidation process, which can be attributed to the increased stiffness of this constituent induced by the thermal-oxidation. Actually, composites are generally designed so that the reinforcements concentrate the stresses. Moreover, in practice, damage and failure initially often takes place in the subsurface of a mechanical part. Thus, an increased stress experienced by the resin of the external ply is, a priori not favorable to the durability of the composite structure. These considerations can help to explain the worst durability of thermo-oxidized composite structures, observed in practice, by comparison with the reference behaviour of the unaffected by oxidation structure.

\section{Conclusions}

In this work, the consequences due to the shrinkage induced by a thermal oxidation process of the epoxy resin constituting a composite structure were investigated, for the first time, through a scale transition approach. The obtained results were compared to finite elements calculations, with a rather good agreement. The scale transition approach demonstrates that the effective properties and mechanical states of the external ply of a composite structure having experienced a thermal oxidation process do not strongly differ from the corresponding reference values of the ply unaffected by the thermal oxidation. On 
the opposite, the local properties and mechanical states of the matrix constituting the ply affected by thermal oxidation and the matrix shrinkage do strongly vary as a function of the thermal oxidation process state. It was demonstrated that both the evolutions of the mechanical properties and mechanical states in the epoxy after the thermal oxidation were not compatible with an enhanced durability of the structure, especially in the case that a transverse external load had to be undergone. Nevertheless, the present approach does not underline that the service life of a composite plate submitted to longitudinal or thermal load would be affected by the thermal oxidation of the epoxy. In further works, others features related to the thermal ageing of organic matrix composites structures, such as high temperature creep, will be investigated.

\section{References}

[1] X. Colin, C. Marais, and J. Verdu, A new method for predicting the thermal oxidation of thermoset matrices; application to an amine crosslinked epoxy, Polym. Test., 20 (7) (2001) 795-803

[2] V. Bellenger, J. Decelle, N. Huet, Ageing of a carbon epoxy composite for aeronautic applications, Composites, Pt. B, 36 (2005) 189-194

[3] P. M. Hergenrother, Development of composites, adhesives and sealants for highspeed commercial airplanes, SAMPE Journal, 36 (2000) 30-41

[4] M.D. Brunner, T. Cebeci, Development of the California State University, Long Beach composite durability laboratory, Proceedings of the International SAMPE Symposium and Exhibition, (1994) 1554-1563 
[5] K.J. Bowles, A. Meyers, Specimen Geometry Effects on Graphite/PMR-15 Composites During Thermo-oxidative Aging, Proceedings of 31st International SAMPE Symposium and Exhibition, (1986) 1285-1299

[6] M.S. Madhukar, K.J. Bowles, D.S. Papadopoulos, Thermo-oxidative stability and fiber surface modification effects on the Inplane shear properties of graphite/PMR-15 Composites, Journal of Composite Materials, 31 (6) (1997) 596-618

[7] L. Olivier, N. Q. Ho, J.C. Grandidier, M.C. Lafarie-Frenot, developement of experimental, theorical and numerical tools for studying thermo-oxydation of CFRP composites, Composites: Part A, 40 (2009) 1008-1016

[8] X. Colin, C. Marais, J. Verdu, Kinetic modelling and simulation of gravimetric curves: application to the oxidation of bismaleimide and epoxy resins, Polymer Degradation and Stability 78 (2002) 545-553

[9] G.P. Tandon, K.V. Pochiraju, G.A. Schoeppner, Modeling of oxidative development in PMR-15 resin, Polym. Degrad. Stabil., 91 (2006) 1861-1869

[10] J. M. Sprauel, L. Castex, , First European Powder Diffraction International Conference on X-Ray stress analysis, Munich (1991)

[11] S. Fréour, F. Jacquemin, R. Guillén, On an analytical self-consistent model for internal stress prediction in fiber-reinforced composites submitted to hygroelastic load, J. Reinf. Plast. Compos., 24 (2005) 1365-1377

[12] W. Voigt, Lehrbuch der Kristallphysik, Teubner, Leipzig/Berlin (1928).

[13] A. Reuss, Berechnung der Fliessgrenze von Mischkristallen auf Grund der Plastizitätsbedingung für Einkristalle, Z. Angew. Math. Mech., 9, (1929) 49-58

[14] H. Neerfeld, Zur Spannungsberechnung aus röntgenographischen Dehnungsmessungen, Mitt. Kaiser-Wilhelm-Inst. Eisenforschung Düsseldorf, 24 (1942) 61-70 
[15] R. Hill, The elastic behaviour of a crystalline aggregate, Proc. Phys. Soc., 65 (1952) 349-354

[16] S. W. Tsai, H. T. Hahn, Introduction to Composite Materials, Technomic Publishing Co., Inc., Lancaster, Pennsylvania (1980).

[17] K.Tanaka, T.Mori, The Hardening of Crystals by Non-deforming Particules and Fibers, Acta Metallurgica, 18 (1970) 931-941

[18] T. Mori, K. Tanaka, Average Stress in Matrix and Average Elastic Energy of Materials with Misfitting Inclusions, Acta Metallurgica, 21 (1973) 571-574

[19] F. Jacquemin, S.Fréour, R. Guillen, A hygro-elastic self-consistent model for fiberreinforced composites, Journal of Reinforced Plastics and Composites, 24 (2005) $485-502$

[20] S. Fréour, F. Jacquemin, R. Guillén, Extension of Mori-Tanaka approach to hygroelastic loading of fiber-reinforced composites - Comparison with EshelbyKröner self-consistent model, J. Reinf. Plast. Compos., 25 (2006) 1039-1052

[21] J. D. Eshelby, The determination of the elastic field of an ellipsoidal inclusion, and related problems, Proc. Roy. Soc., A241 (1957) 376-396

[22] E. Kröner, Berechnung der elastischen Konstanten des Vielkristalls aus des Konstanten des Einkristalls, Z. Phys., 151 (1958) 504-518

[23] U. F. Kocks, C. N. Tomé, H. R. Wenk, Texture and Anisotropy, Cambridge University Press, (1998).

[24] T. Mura, Micromechanics of Defects in Solids, Martinus Nijhoff Publishers, The Hague, Netherlands, (1982).

[25] K.J. Bowles, M.S. Madhukar, D.S. Papadopoulos, L. Inghram, , L. Mc Corkle, , The effect of fiber surface modification and thermal aging on composite toughness and its measurement, J. Comp. Mat., 6 (1997) 552-579 
[26] P. D. Soden, M. J. Hinton, and A. S. Kaddour, Lamina properties lay-up configurations and loading conditions for a range of fiber-reinforced composite laminates, Compos. Sci. Technol., 58 (1998) 1011-1022

[27] B. P. Patel, M. Ganapathi, and D. P. Makhecha, Hygrothermal effects on the structural behaviour of thick composite laminates using higher-order theory, Compos. Struct., 56 (2002) 25-34

[28] R. Hill, Continuum micro-mechanics of elastoplastic polycrystals, J. Mech. Phys. Solids, 13 (1965) 89-101

[29] R. Morris, Elastic constants of polycrystals, Int. J. Eng. Sci., 8 (49) (1970)

[30] T.S. Gates, L.C. Brinson, Acceleration of Aging in Graphite/Bismaleimide and Graphite/Thermoplastic Composites. AIAA Paper 94 (1582) (1994) 2096-2105

[31] M.C. Lafarie-Frenot, S. Rouquie, Influence of oxidative environments on damage in c/epoxy laminates subjected to thermal cycling, Composites Science and Technology, 64 (2004) $1725-1735$

[32] J. Decelle, N. Huet, V. Bellenger, Oxidation induced shrinkage for thermally aged epoxy networks, Polymer Degradation and Stability, 81 (2003) 239-248

[33] Soden, P. D., Hinton, M. J. and Kaddour, A. S., Lamina Properties Lay-up Configurations and Loading Conditions for a Range of Fiber-reinforced Composite Laminates, Composites Science and Technology, 58, (1998), 1011-1022. 
Figure legends

Figure 1: Evolution of the elastic modulus as a function of the oxidation products concentration. Comparison with the behavior of unaffected matrix.

Figure 2. Longitudinal macroscopic effective elastic modulus of a composite ply, as a function of the oxidation products concentration.

Figure 3. Transverse macroscopic effective elastic modulus of a composite ply, as a function of the oxidation products concentration.

Figure 4. Evolution of the longitudinal $\left(M_{11}\right)$ and transverse $\left(M_{22}\right)$ macroscopic coefficients of thermal expansion, as a function of the oxidation products concentration.

Figure 5: Longitudinal $\left(\sigma_{11}\right)$ and transverse $\left(\sigma_{22}\right)$ stresses concentrations in the constituents of the oxidized external ply, the composite structure being subjected to a transverse stress $\sigma_{22}=50 \mathrm{MPa}$.

ST: scale-transition, comp: composite, mat: matrix, FEM: finite element method.

$Q$ stands for the oxidation products concentration.

Figure 6. Effects of shrinkage on the longitudinal $\left(\sigma_{11}\right)$ and transverse $\left(\sigma_{22}\right)$ stresses concentrations in the constituents of the oxidized external ply, the composite structure being subjected to a transverse stress $\sigma_{22}=50 \mathrm{MPa}$.

ST: scale-transition, comp: composite, mat: matrix, FEM: finite element method.

Q stands for the oxidation products concentration. 
Tables

Table 1. Properties of T300 carbon fiber [33].

\begin{tabular}{|c|c|c|c|c|}
\hline$Y_{1}(\mathrm{GPa})$ & $\mathrm{Y}_{2}, \mathrm{Y}_{3}(\mathrm{GPa})$ & $\mathrm{v}_{12}, \mathrm{v}_{13}$ & $\mathrm{G}_{12}(\mathrm{GPa})$ & $\mathrm{G}_{23}(\mathrm{GPa})$ \\
\hline 230 & 15 & 0.2 & 15 & 7 \\
\hline
\end{tabular}




\section{Figures}

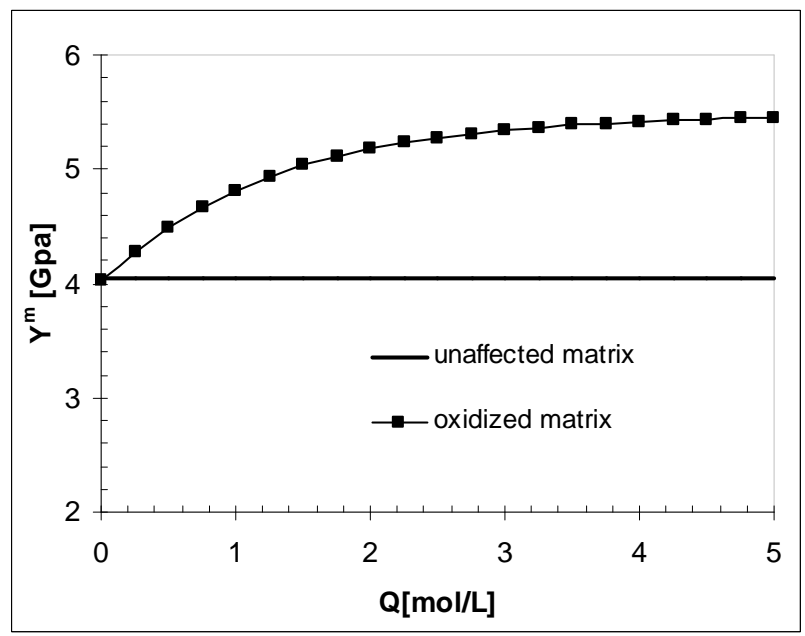

Figure 1: Evolution of the elastic modulus as a function of the oxidation products concentration. Comparison with the behavior of unaffected matrix. 


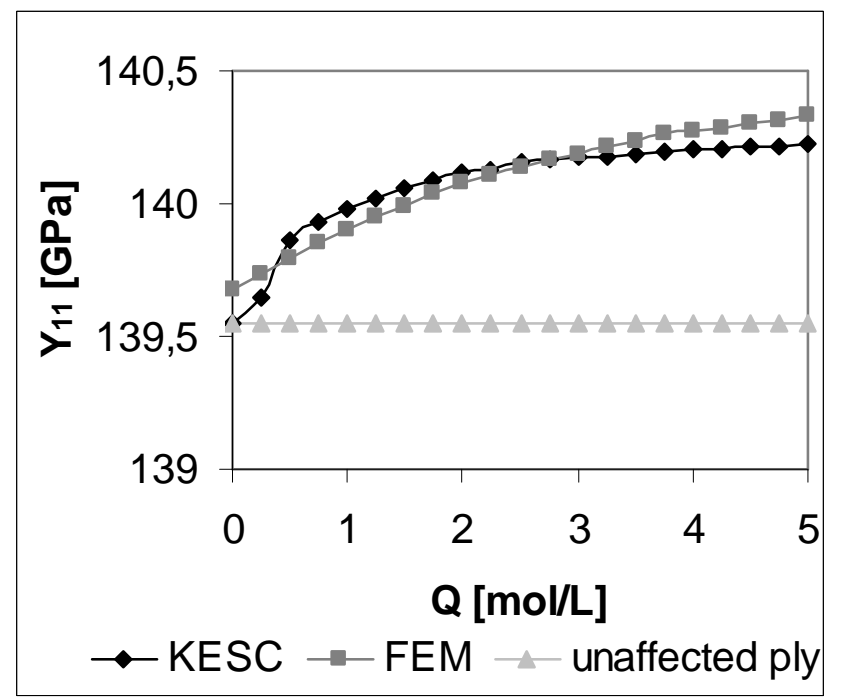

Figure 2. Longitudinal macroscopic effective elastic modulus of a composite ply, as a function of the oxidation products concentration. 


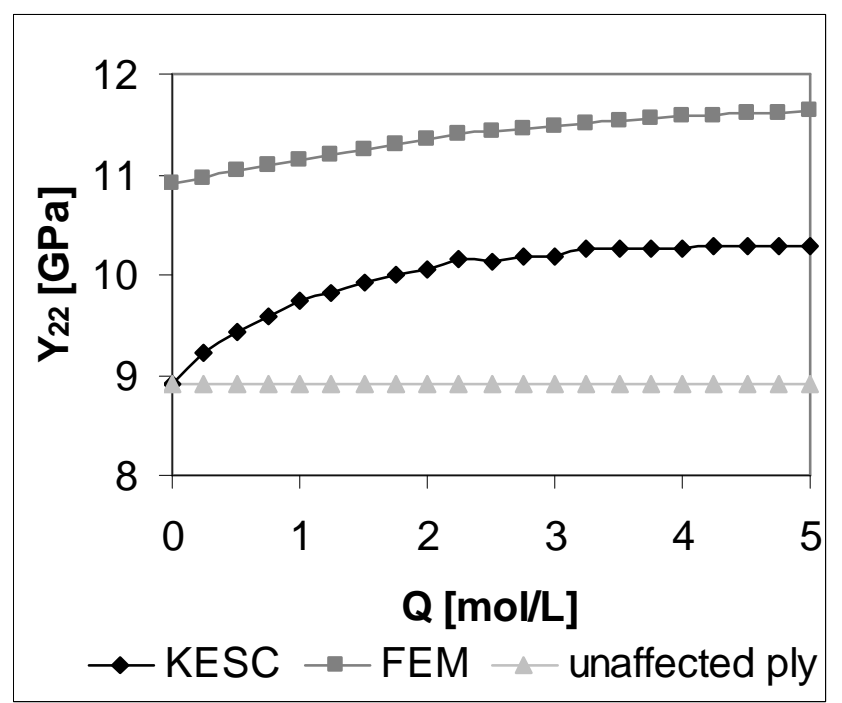

Figure 3. Transverse macroscopic effective elastic modulus of a composite ply, as a function of the oxidation products concentration. 

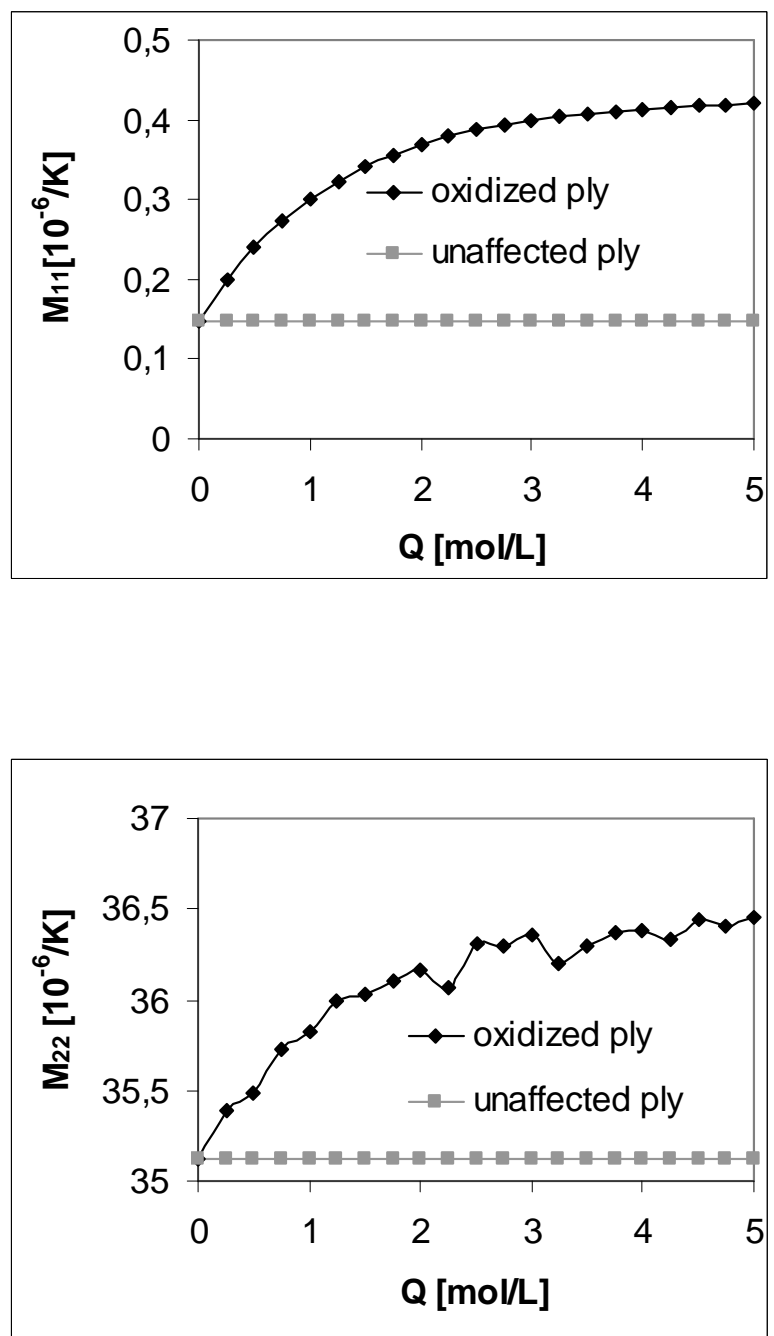

Figure 4. Evolution of the longitudinal $\left(M_{11}\right)$ and transverse $\left(M_{22}\right)$ macroscopic coefficients of thermal expansion, as a function of the oxidation products concentration. 


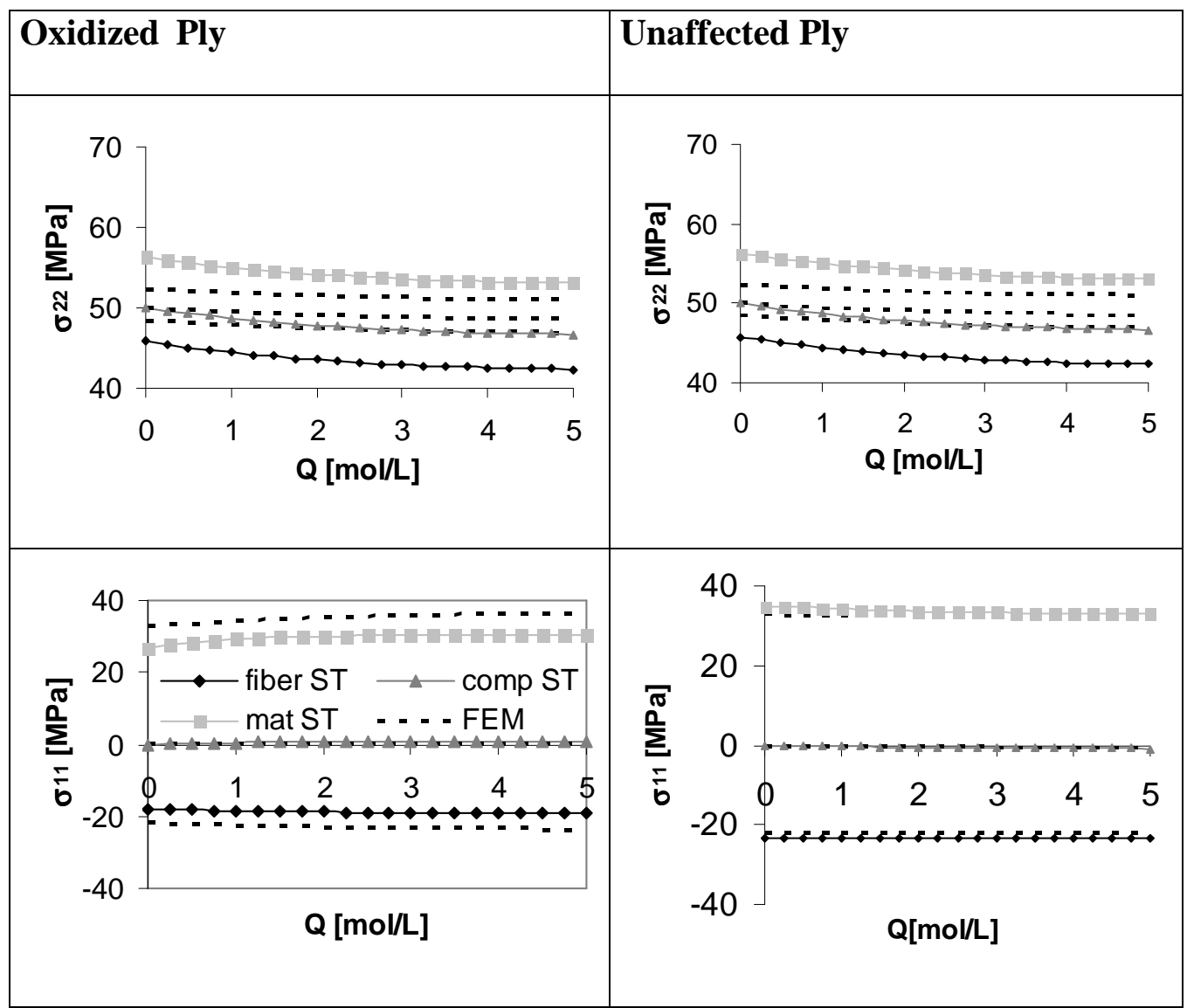

Figure 5: Longitudinal $\left(\sigma_{11}\right)$ and transverse $\left(\sigma_{22}\right)$ stresses concentrations in the constituents of the oxidized external ply, the composite structure being subjected to a transverse stress $\sigma_{22}=50 \mathrm{MPa}$.

ST: scale-transition, comp: composite, mat: matrix, FEM: finite element method.

Q stands for the oxidation products concentration. 


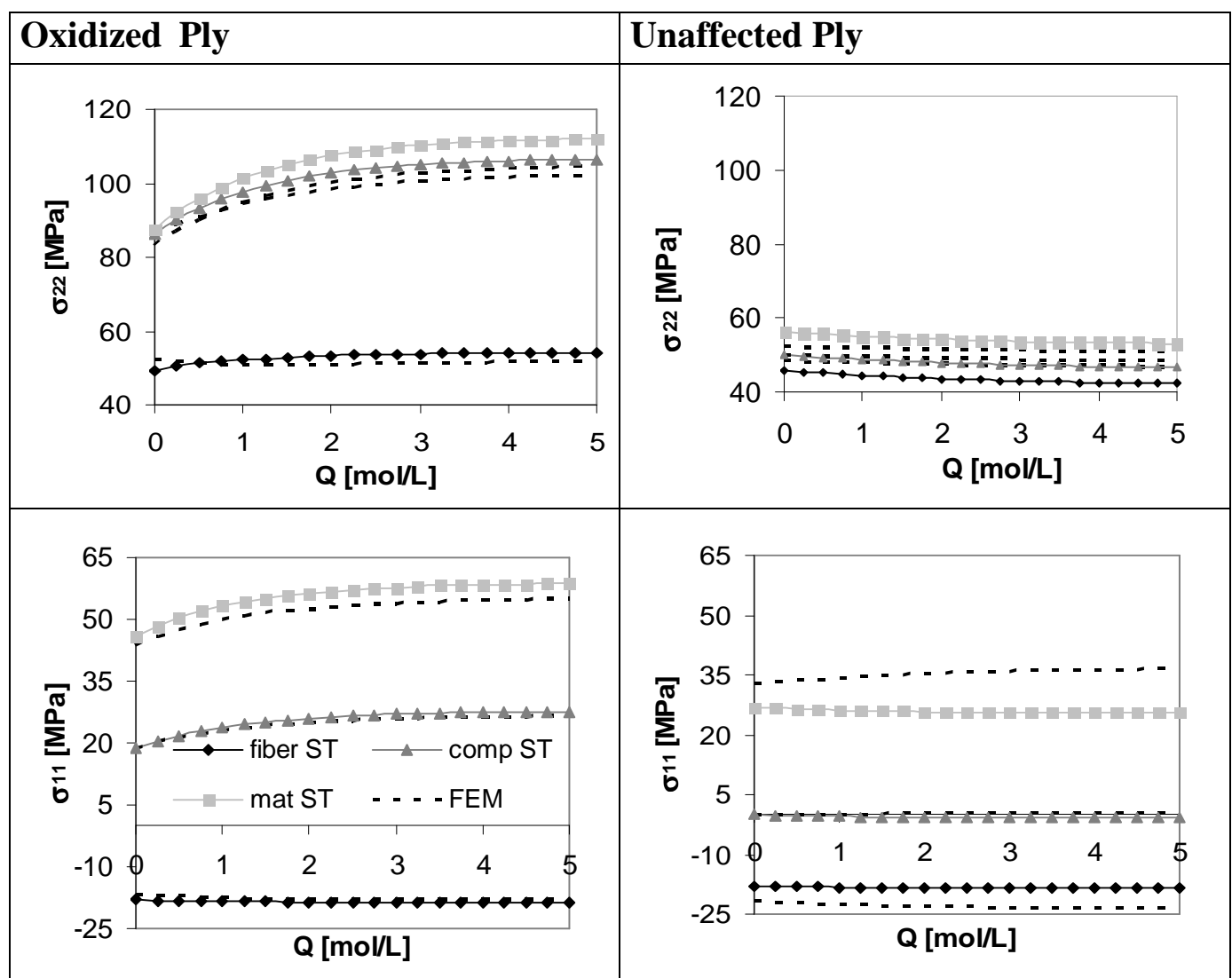

Figure 6. Effects of shrinkage on the longitudinal $\left(\sigma_{11}\right)$ and transverse $\left(\sigma_{22}\right)$ stresses concentrations in the constituents of the oxidized external ply, the composite structure being subjected to a transverse stress $\sigma_{22}=50 \mathrm{MPa}$.

ST: scale-transition, comp: composite, mat: matrix, FEM: finite element method.

Q stands for the oxidation products concentration. 